\title{
ОЦІНКА ЯК КАТЕГОРІЯ ПРАГМАТИКИ СУЧАСНОГО МОЛОДІЖНОГО ОНЛАЙН-СЛЕНГУ
}

Статтю присвячено дослідженню тексико-семантичних і прагматичних аспектів німецького молодіжного онлайн-сленгу на матеріалі соціальних мереж, інтернет-сторінок та чатів. Актуалізовано терміни "сленг”, "прагматика", проаналізовано основні особливості мовної картини світу молоді на прикладі використання одиниць, що виражають аксіологічні відтінки значень. Установлено особливості системної організації сленгової лексики і їі поділ на різнопланові тематичні та оцінні групи. Класифіковано досліджені лексичні одиниці з огляду на позитивну чи негативну конотацію в онлайнкомунікації сучасної німецькомовної молоді.

Ключові слова: оцінка, прагматика, онлайн, сленг, молодь, комунікація.

\section{Teslia V., Nesterenko N. Evaluation as a Category of Pragmatics of Mod-} ern Youth Online Slang. At the present stage of the study of language units there is an increased interest in the research of youth speech, which expresses the attitude of young people to the surrounding reality and the desire to stand out in a separate socio-age group. The relevance of the study is the analysis of units of youth speech with an evaluative component, which serve to exchange information, express emotions, feelings and attitudes to objects, events and phenomena of the environment.

We see the purpose of the study in examination of the lexical and semantic aspects of German youth online slang on the basis of social networks, websites and chats.

To achieve this goal, we consider it appropriate to solve the following tasks: definition of slang, pragmatics; analysis of the main features of the linguistic picture of the world of youth, taking into account the vocabulary that expresses a certain degree of evaluation.

The article presents the features of German youth online slang and its analysis, explains the reason for its occurrence. Youth slang is presented as the most dynamic language system, mirroring the new social paradigm of language functioning. The purpose of functioning of German youth slang is established, the vocabulary with positive, negative and neutral connotation is analyzed.

Globalization and intercultural exchange contribute to the uniting of different cultures of the same types of leisure, which promotes the emergence of identical borrowings. In the thematic context, the youth vocabulary has different thematic groups. In the language of youth, there are tangible motives for self-expression and separation. Analogies and parallelism in the creation of youth slang in the German language are evident as well as a specific cultural aspect and the use of certain lexemes that are distinct to a particular language and culture. 
As a result of studying the analyzed language units, the peculiarities of the system organization of slang vocabulary are established and its division into various thematic and evaluation groups is carried out; positive and negative connotations of the vocabulary for expression of evaluation in online communication of modern German-speaking youth are structured.

Key words: assessment, pragmatics, online, slang, youth, communication.

\section{Вступ}

На сучасному етапі дослідження мовних одиниць спостерігаємо посилений інтерес до вивчення молодіжного мовлення, у якому комуніканти дають оцінку довкіллю, чим виражають бажання виокремитися в окрему соціально-вікову групу. Наразі інтернет здійснює доволі сильний вплив на спілкування серед молоді, що також перебуває у фокусі уваги мовознавців. Дослідники вивчають особливості комунікації молодих людей з урахуванням реалій їхнього життя, аналізуючи відповідні аспекти на матеріалі одиниць різних мовних рівнів.

Молодь займає активну позицію в житті суспільства, і шляхом аналізу вживаних мовних одиниць можна отримати інформацію щодо інтересів, уподобань, настроїв та ставлення молодих людей до певних подій, об’єктів, явищ, що їх оточують.

Вивчення оцінки знайшло своє відображення в працях таких науковців: Н. Д. Арутюнової, Ф. С. Бацевича, О. М. Вольф, В. Г. Гака, Г. Г. Почепцова, В. М. Телії, Н. М. Вахтель, О. О. Селіванової, И. П. Сусова, Т. І. Приходька, Л. М. Марчук, В. Л. Крищук, О. С. Шатілової, М. 3. Конєвої та ін. Результати досліджень зазначених учених використовуємо як основу для аналізу оцінного аспекту молодіжного онлайн-сленгу сучасної німецькомовної молоді.

Оцінні особливості лексики німецькомовного сленгу потребують додаткового вивчення, що засвідчує актуальність нашого дослідження - аналізу сленгу німецькомовної молоді, який містить оцінні компоненти, слугує для обміну інформацією, вираження емоцій, почуттів та ставлення до об’єктів, подій, явищ довкілля.

Мету дослідження вбачаємо у вивченні лексико-семантичних аспектів, а також аналізі прагматичного потенціалу оцінних мовних одиниць німецького молодіжного онлайн-сленгу на матеріалі соціальних мереж, інтернет-сторінок та чатів. Для досягнення поставленої мети доцільним уважаємо розв'язання таких завдань: 1) актуалізація понять “сленг”, “прагматика”; 2) аналіз особливостей лексики, 
що виражає оцінні відтінки значень як складника мовної картини світу молоді.

\section{Методи дослідження}

Для вивчення оцінки як категорії прагматики сучасного молодіжного онлайн-сленгу було застосовано такі методи: метод індукції (узагальнення результатів спостережень), аналізу та синтезу (конкретизація отриманих знань й узагальнення результатів досліджень), аналіз словникових дефініцій (визначення семантики досліджуваних мовних одиниць), методики контекстуально-ситуативного й прагматичного аналізів (установлення особливостей функціонування молодіжної лексики для вираження оцінки в онлайн-контексті та її впливу на адресата).

\section{Виклад основного матеріалу}

Активізацію дослідження мови з урахуванням іiі прагматичних характеристик спостерігаємо в межах загального антропоцентричного підходу в лінгвістиці кінця XX - початку XXI ст. Здійснення лінгвопрагматичних досліджень вимагає доволі складного інтегрованого підходу, що передбачає аналіз мовних явищ із застосуванням категорій і методик психології, соціології, логіки, семіотики.

Як зазначає I. П. Сусов, «прагматика не може не спиратися на уявлення про мову як систему засобів та правил, але вона робить акцент на комунікативних процесах та контекстуально залежних принципах використання даної системи у безкінечній кількості різноманітних актів мовного спілкування» (Сусов, 2009: 133).

Широке розуміння меж прагматики, за словами О. О. Селіванової, дає змогу характеризувати іiі як міждисциплінарну галузь теорії комунікації, що пов'язана практично з усіма лінгвістичними напрямами, а також низкою інших наук, тим чи тим способом пов'язаних зі спілкуванням (Селіванова, 1999).

Слід підкреслити, що комунікація здійснюється передусім за допомогою конкретних мовних засобів, що відповідно впливають на реципієнта. Аспекти спілкування, пов'язані з впливом комунікантів один на одного за допомогою мовних засобів, називають прагматичними, оскільки вони безпосередньо залежать від учасників комунікації і стосунків між ними (Вольф, 1985: 105-108). 
Орієнтуючись на ситуацію, адресант використовує конкретні мовні засоби, що допоможуть йому реалізувати свій задум у процесі комунікації. При цьому визначну роль відіграє характер комунікативної ситуації, адже маркером прагматики мовлення, зокрема й молодіжного, є мотив, який є основою комунікативного наміру (Вахтель, 2006: 68-79).

Онлайн-мовлення німецької молоді характеризується передусім оцінним наповненням цілої низки наведених нижче аспектів характеристики адресата:

- інформованості (Bodenturner - Dummkopf; Brotgehirn - Idiot, dummer Mensch; Denkzwerg - Dummkopf; Evolutionsbremse - Idiot; Fischkopf-Dummkopf) (Duden; Kleines Wörterbuch der Jugendsprache);

- зовнішнього вигляду співрозмовника (Hottie - attraktive Person; Der pure Ranz - ungepflegte Person; Gesichtswurst - hässliche Person, kat$z e$ - leichtfüßig, elegant) (Duden; Kleines Wörterbuch der Jugendsprache);

- поглядів на життя (Alman - ein Mensch, der sich dem deutschen Klischee entsprechend verhält) (Duden; Kleines Wörterbuch der Jugendsprache);

- психологічного стану (Straight shooter - ein direkter, ehrlicher Mensch, der Schwarm - der geliebte Mensch; Darmatmer - unangenehme Person) (Duden; Kleines Wörterbuch der Jugendsprache);

- особливостей характеру, поведінки (Faultier - fauler Mensch; Weichei - ein feiger Mensch; Pommesgrab - langweilige Person, Smombie - beschreibt jemanden, der von seiner Umwelt nichts mehr mitbekommt, weil er nur auf sein Smartphone starrt (Smartphone + Zombie)) (Duden; Kleines Wörterbuch der Jugendsprache);

- розумових здібностей (Expresschecker - Mensch mit schnellem Durchblick, intelligenter Mensch) (Duden; Kleines Wörterbuch der Jugendsprache).

Наведені вище приклади ілюструють тенденцію вираження співрозмовником оцінки відповідно до рівня інформованості про адресата й особливостей його сприйняття. Слід звернути особливу увагу на те, що саме в цій групі кількісно переважають лексичні одиниці 3 негативною конотацією.

В онлайн-комунікації спостерігаємо також оцінку власне змісту висловлення, де фіксуємо такі їі аспекти: 
- істинність / неістинність (Bullshit - Blödsinn) (Duden; Kleines Wörterbuch der Jugendsprache);

- схвалення / засудження (gordig - schlecht; Grottenschlecht - sehr schlecht; lash - schlecht, lahm; madig - schlecht; plurice - schlecht, unpassend, blöd; schmando - schlecht; knusper - gut; lecker - gut aussehend; marmor sehr gut, cool; phat - sehr gut; schmusig - gut, okay; total mega geil - sehr sehr gut; vierlagig - extrem gut) (Duden; Kleines Wörterbuch der Jugendsprache);

- важливість / неважливість (akk - egal; bums - egal, einerlei; genascht - egal, unwichtig; lachs - egal, unwichtig) (Duden; Kleines Wörterbuch der Jugendsprache);

- ясність / незрозумілість (gnarf, alles gnarf - alles klar; klaro - klar; lockerlich - klar) (Duden; Kleines Wörterbuch der Jugendsprache);

- справедливість / несправедливість (etwas fair finden - etwas für gerecht halten) (Duden; Kleines Wörterbuch der Jugendsprache);

- позитивне / негативне ставлення (bombe - sehr gut, toll; bosshaft extrem cool, luxuriös, chefmäßig; bossig - extrem cool, luxuriös, chefmäßig; ceil - Mischung aus cool und geil; cheedo - cool; chillig - angenehm zu hören) (Duden; Kleines Wörterbuch der Jugendsprache) (Вольф, 1985: 102-112).

Тож, ураховуючи наведені вище приклади, можемо узагальнити, що негативна оцінка найчастіше стосується конкретної особи, водночас оцінка самого висловлення передусім характеризується позитивним відтінком і схваленням співрозмовника.

Висловлення 3 оцінними компонентами досить різноманітні. О. М. Вольф називає оцінними не лише ті лексичні одиниці, що містять оцінні слова із синонімічного ряду “добре” / “погано”, але й багато інших одиниць з яскраво вираженою оцінною семою (Вольф, 1985: 109).

У своїх досідженнях О. О. Селіванова дотримується думки Дж. Р. Серля, що виділяє п'ять основних категорій мовленнєвих актів: асертиви, директиви, комісиви, експресиви й декларативи. В аспекті аналізу аксіологічно маркованих мовних одиниць увагу передусім привертають експресиви, за допомогою яких адресат виражає свої почуття й емоції (Селіванова, 1999).

О. М. Вольф уважає за доцільне розуміння класу експресивів у широкому розумінні, ураховуючи висловлення, обумовлені соціальними конвенціями (вибачення, подяку, привітання та ін.), і ті, що передусім характеризуються зображенням психічного стану мовця 
та здійсненням емоційного впливу на реципієнта. Проте слід зауважити, що не завжди метою оцінки є саме емоційний вплив на співрозмовника. Розглядаючи увесь спектр можливих комунікативних ситуацій, дослідниця припускає, що іноді адресанту достатньо згоди адресата або підтвердження ним певної інформації. Однак складність узгодження й узагальнення цих процесів пояснюється їхніми антропоцентричними та ситуативними особливостями, що є значною перешкодою, яка уповільнює процес досліджень (Вольф, 1985: 106-108).

Тож, узявши за основу наукові розвідки Дж. Р. Серля та О. М. Вольф, ми розподілили проаналізовані мовні одиниці онлайн-діалогів сучасної німецькомовної молоді за типом оцінок з урахуванням комунікативно-функціонального аспекту:

1. Лексика для вираження позитивної оцінки:

- Adjektive und Adverbien (cheedo - cool; fickbar - attraktiv; geilo meilo - cool; gril - geil ; lit - sehr cool mega toll) (Duden; Kleines Wörterbuch der Jugendsprache);

- Verben (abspacken - herumalbern, sich freuen; bashen - besiegen; bocken - Spaß machen; drauf sein - sich gut fühlen) (Duden; Kleines Wörterbuch der Jugendsprache);

- Substantive (Player/Playa - gut aussehender Junge; Rotzbremse Schnurrbart; Schnitzel - hübscher Mensch; Wingman/Wingwoman - person, welche behilflich ist, jemanden anzubaggern) (Duden; Kleines Wörterbuch der Jugendsprache);

- Phraseologismen (Alles gucci - Alles in Ordnung; Läuft bei Dir! - ironisch: Du hast Glück, Alles perfekt!; Na logo! - natürlich!; Voll Rotlichtmassaker! - unglaublich, krass) (Duden; Kleines Wörterbuch der Jugendsprache);

- Redewendungen (Krasse Pasta sein - voll geil; Sich einen Kullerkeks freuen - sich sehr auf etwas freuen; Übelst Schloss Neuschwanstein - verdammt cool; Übelst Weltraum - sehr geil, kaum zu glauben; Voll Bock haben - Lust haben) (Duden; Kleines Wörterbuch der Jugendsprache);

- Abkürzungen (LOL - laut auflachen; ROFL, ROFLMAO - lachend über den Boden rollen; $x D$, icks deh - Echt lustig!, Hahah! Um 90-Grad gedrehtes Gesicht. Das X soll dabei die vor Lachen zugedrückten Augen zeigen, während das D für den lachenden Munde steht; XOXO - Umarmung und Küsschen; XXX - Das Dreifach-X wird unter Freunden als Abkürzung für "kiss kiss kiss" im Englischen genutzt) (Duden; Kleines Wörterbuch der Jugendsprache); 
2. Лексика для вираження негативної оцінки, що репрезентована такими частинами мови:

- Adjektive und Adverbien (derb, derbs - schlimm, heftig; gaga - übergeschnappt, verrückt, meschugge, durchgeknallt; larry - Wenn jemand extrem dumm ist, oder dummes Zeug labert; schmandig - ekelig, schmierig; schmando - schlecht; schmoppseln - Beschreibung einer nervigen, unangenehmen Sache; schabernack - sarkastisch; verbuggt - voller Fehler, falsch gestrickt) (Duden; Kleines Wörterbuch der Jugendsprache);

- Verben (abkacken - sich langweilen; bomben - fertigmachen; flexen angeben; merkeln - nichts tun, keine Entscheidung treffen; sucken - nerven) (Duden; Kleines Wörterbuch der Jugendsprache);

- Substantive (Bambusleitung - schlechte Internetverbindung; Banalverkehr - belangloser Chatverlauf; Dizzer - jemand, der jeden schräg anmacht; Hasslatte - schlechte Laune, Wut; Interneteier - Mut, nur online laut zu sein) (Duden; Kleines Wörterbuch der Jugendsprache);

- Redewendungen (Anzeige ist raus! - Ironischer Spruch, wenn jemand etwas Verbotenes macht; Aufkeinsten - aufkeinen Fall; Back Dir ein Eis! - Hau ab! Texte mich nicht zu!) (Duden; Kleines Wörterbuch der Jugendsprache);

- Abkürzungen (31er - Verräter; IDES - Ist das ein Scheiss; IHAM! - Ich hasse alle Menschen; Lmgtfy (let me google that for you) - Ausdruck, wenn jemand eine unnötige Frage stellt, die auch Google beantworten kann) (Duden; Kleines Wörterbuch der Jugendsprache).

3. Лексика для вираження нейтральної оцінки:

- Adjektive und Adverbien (akk - egal; klaro - klar; semi-rofl - halblustig; shisha - sicher) (Duden; Kleines Wörterbuch der Jugendsprache);

- Verben (durch sein - verrückt sein; funzen - funktionieren; jemandem rille sein - egal sein; mailden - per Mail melden; raffen - verstehen; saugen - downloaden; telen - telefonieren) (Duden; Kleines Wörterbuch der Jugendsprache);

- Substantive (Appler - eine Person, die mit seinem Apple-Produkt angibt, also ein Apple-Angeber, Anspielung auf Getränk «Äppler»; Googleschreiber - Person, die die URL bei Google eingibt; Igers - Instagrammer; Mauke - Lust; Mecces - McDonald's; Tindergarten - Sammlung von Onlinedating-Kontakten; Tschuligom - Entschuldigung) (Duden; Kleines Wörterbuch der Jugendsprache);

- Ausrufe (Boah! - Ausruf des Staunens; Fix, Oida! - Sicher! Klar!; He! - Ausruf der Erstaunen; Juckts? - Wen interessiert's?; Keinen Turn 
haben - in schlechter Stimmung sein; Sheeeesh - Wirklich? Echt jetzt? Nicht dein Ernst!?; Uiuiui - Ausruf des Lachens; Wallah - Ausrufder Überraschung; Yalla! - Beeil dich!) (Duden; Kleines Wörterbuch der Jugendsprache);

- Phraseologismen (Alles Banane! - Alles klar! Alles in Ordnung!; Auf dein Nacken! - Auf keinsten - auf keinen Fall; Geh bei Grün! - bleib entspannt!; Hängs! - Vergiss es!; I bims - Ich bin's) (Duden; Kleines Wörterbuch der Jugendsprache);

- Abkürzungen (BD - bis dann; IDA - Ich Dich Auch; kA - keine Ahnung; Vlt. and Vllt - Vielleicht; WD - Wieder da) (Duden; Kleines Wörterbuch der Jugendsprache).

Проведений аналіз мовних одиниць у молодіжній онлайн-комунікації дав змогу виокремити лексику для вираження позитивної, негативної і нейтральної оцінки. Досліджувані одиниці представлені різними частинами мови (прикметники, прислівники, дієслова, іменники, вигуки), а також фразеологізмами та скороченнями.

\section{Висновки}

Отже, оцінка як категорія прагматики є невід’ємним компонентом комунікації, зокрема сучасного молодіжного онлайн-сленгу, і слугує не лише елементом емоційно-експресивного підсилення емоційності висловлення, а й здійснює вплив на адресата. Проаналізувавши лексику з позитивною і негативною конотацією на матеріалі німецькомовних соціальних мереж, інтернет-сторінок та чатів, можемо зробити висновок, що негативна оцінка найчастіше стосується конкретної особи, тоді як оцінка самого висловлення здебільшого демонструє позитивне ставлення до комунікативного партнера. Лексика для вираження нейтральної оцінки в молодіжному мовленні переважно позначає конкретні дії користувачів соціальних мереж й моделює вислови без експресивно-емоційного навантаження. Дослідивши основні особливості мовної картини світу молоді, ураховуючи лексичні одиниці, що виражають певну оцінку, прослідковуємо бажання молодих людей виокремитися в самостійну соціальну групу й реагувати на відповідні події та явища довкілля, використовуючи емоційно забарвлені мовні одиниці.

Перспективу дослідження вбачаємо у вивченні походження лексичних одиниць німецькомовного молодіжного сленгу. 


\section{ЛITЕРАТУРА}

1. Бацевич, Ф. С. (2004). Основи комунікативної тінгвістики. Київ: ВЦ «Академія». 2. Вахтель, Н. М. (2006). Основы прагмалингвистики. Воронеж: Изд-во ВГУ. 3. Вольф, Е. М. (1985). Функииональная семантика оценки. Москва: URSS. 4. Конєва, М. 3. (2009). Оцінка у фокусі функціонально-комунікативної парадигми. Вісн. Харк. наи. ун-ту імені В. Н. Каразіна. Серія «Філологія», 1124, 126-132. 5. Крищук, В. Л. (2015). Вербалізація оцінки в українській історичній прозі кінця XX - початку XXI ст. (Дис. ... канд. філол. наук). Кам'янець-Подільський: Кам'янець-Поділ. нац. ун-т імені Івана Огієнка. 6. Приходько, Т. І. (2002). Способи вираження оцінки в сучасній англійській мові. Запоріжжя: Вид-во ЗДУ. 7. Селіванова, О. О. (1999). Актуальні напрямки сучасної лінгвістики (аналітичний огляд). Київ: Вид-во Укр. фіто соціолог. центру. 8. Сусов, И. П. (2009). Лингвистическая прагматика. Винница: Нова книга. 9. Шатілова, О. С. (2017). Оцінність як категорія текстів в українських засобах масової комунікації. Studia philologica, 8, 74-77. 10. Duden: Online-Wörterbuch. Узято з https://www.duden.de/ woerterbuch. 11. Kleines Wörterbuch der Jugendsprache. Узято 3 www.t-online.de/leben/familie/schulkind-und-jugendliche/id_18055098/lauchehrenmann-und-co-kleines-woerterbuch-der-jugendsprache.html.

\section{REFERENCES}

1. Batsevych, F. S. (2004). Osnovy komunikatyvnoi linhvistyky [Fundamentals of communicative linguistics]. Kyiv: VTs «Akademiia» [in Ukrainian]. 2. Vakhtel, N. M. (2006). Osnovy prahmalynhvystyky [Fundamentals of pragmalinguistics]. Voronezh: Yzd-vo VHU [in Russian]. 3. Volf, E. M. (1985). Funkcional'naya semantika ocenki. [Functional semantics of evaluation]. Moskva: URSS [in Russian]. 4. Konieva, M. Z. (2009). Otsinka $\mathrm{u}$ fokusi funktsionalno-komunikatyvnoi paradyhmy [Assessment in the focus of the functional-communicative paradigm]. Visn. Khark. nats. un-tu imeni V. N. Karazina. Seriia «Filolohiia» - Bulletin of VN Karazin Kharkiv National University. Philology Series, 1124, 126-132 [in Ukrainian]. 5. Kryshchuk, V. L. (2015). Verbalizatsiia otsinky v ukrainskii istorychnii prozi kintsia XX - pochatku XXI st. [Verbalization of evaluation in Ukrainian historical prose of the late XX - early XXI centuries]. Candidate's thesis. Kamianets-Podilskyi: Kamianets-Podil. Nats. un-t imeni Ivana Ohiienka [in Ukrainian]. 6. Prykhodko, T. I. (2002). Sposoby vyrazhennia otsinky v suchasnii anhliiskii movi [Ways of expressing evaluation in modern English]. Zaporizhzhia: Vyd-vo ZDU [in Ukrainian]. 7. Selivanova O.O. (1999). Aktualni napriamky suchasnoi linhvistyky (analitychnyi ohliad) [Current directions of modern linguistics (analytical review)]. Kyiv: Vyd-vo Ukr. fitosotsioloh. tsentru [in Ukrainian]. 8. Susov, Y. P. (2009). Lynhvystycheskaia prahmatyka [Linguistic pragmatics]. Vynnytsa: Nova knyha [in Ukrainian]. 9. Shatilova, O. S. (2017). Otsinnist yak katehoriia tekstiv v ukrainskykh zasobakh masovoi komunikatsii [Evaluation as a category of texts in the Ukrainian mass media]. Studia philologica, 8, 74-77. 10. Duden: Online-Wörterbuch. Retrieved from https://www.duden.de/woerterbuch [in German]. 11. Kleines Wörterbuch der Jugendsprache. Retrieved from www.t-online.de/leben/ familie/ schulkind-und-jugendliche/id_18055098/lauch-ehrenmann-und-co-kleines-woerterbuch-der-jugendsprache. html [in German]. 
Тесля Вікторія Анатолї̈ва - кандидат філологічних наук, доцент, доцент кафедри німецької філології, Черкаський національний університет імені Богдана Хмельницького; вул. Припортова, буд. 8, кв. 85, Черкаси, 18016, Україна.

Tel.: +38-097-511-15-87

E-mail: Viktoria.k.07@ukr.net

https://orcid.org/0000-0002-5095-2873

Teslia Viktoriia Anatoliivna - Candidate of Philological Sciences (Ph.D.), Docent, Associate Professor at the Department of German Philology, Bohdan Khmelnytskyi Cherkasy National University, 8 Priportova Str., Apt. 85, Cherkasy, 18016, Ukraine.

Нестеренко Надія Вячеславівна - студентка Інституту іноземних мов, Черкаський національний університет імені Богдана Хмельницького; вул. Благовісна, 141, с. Думанці, Черкаський район, Черкаська область, 19645, Україна.

Tel.: +38-095-800-22-63

E-mail: nesterenkonadia21@gmail.com

https://orcid.org/0000-0003-2911-9331

Nesterenko Nadiia Viacheslavivna - Student of the Institute of Foreign Languages, Bohdan Khmelnytskyi Cherkasy National University; 141 Blahovisna Str., Dumantsi village, Cherkasy district, Cherkasy region, 19645, Ukraine.

Надійшла до редакції 10 квітня 2021 року

\section{CITATION}

ДСТУ 8302:2015: Тесля В. А., Нестеренко Н. В. Оцінка як категорія прагматики сучасного молодіжного онлайн-сленгу. Лінгвістичні дослідження: зб. наук. пр. Харк. нац. пед. ун-ту імені Г. С. Сковороди. Харків, 2021. Вип. 54. Ч. II. С. 162-171. DOI: https://doi.org/10.34142/23127546.2021.54.2.15

APA: Тесля, В. А., \& Нестеренко, Н. В. (2021). Оцінка як категорія прагматики сучасного молодіжного онлайн-сленгу. Лінгвістичні дослідження, 54 (II), 162-171. DOI: https://doi.org/10.34142/23127546.2021.54.2.15 